- when there was concern that a child's problems might be related to prenatal alcohol exposure.

Results 20 children were assessed in the first year.

8 children were diagnosed as having FASD. Other problems related to conditions such as attachment difficulties, ADHD and learning disability.

There were a small number of children where prenatal alcohol exposure was suspected but unknown, particularly following adoption.

Some children are still awaiting psychological assessment (due to maternity leave) before a diagnosis can be ascribed.

Conclusion It was possible to build in a specialist clinic without significant extra resources.

Additional resources required were a) software required for the facial analysis, and b) training in the use of the 4-digit code (available as an on-line module)

As the clinic developed, an increasing part of the clinic time was taken up with multidisciplinary discussion in 2 areas: what information was available at the time of referral, and what further information/assessments would be required which would be helpful in reaching a diagnosis, and in reaching consensus regarding the final diagnosis.

Informal feedback from teachers, social workers and carers has shown that they have found the clinic helpful and valuable. (formal feedback in progress).

The presence of a specific clinic dedicated to FASD helped provide a focus for referral concerns, develop and concentrate expertise among professionals, and allow ongoing collection of appropriate data.

\section{G161 MULTI PROFESSIONAL WORKING TO DEVELOP A HEALTH OUTCOMES FRAMEWORK FOR CHILDREN IN CARE}

${ }^{1} \mathrm{~V}$ Walker, ${ }^{2} \mathrm{M}$ Bracewell, ${ }^{3} \mathrm{~K}$ Higgins, ${ }^{4} \mathrm{~N}$ Chavaudra. ${ }^{1}$ Community Paediatrics, Sherwood Forest Hospitals NHS Foundation Trust, Mansfield, UK; ${ }^{2}$ Community Paediatrics, Nottingham University Hospitals NHS Trust, Nottingham, UK; ${ }^{3}$ Designated Nurse Children in Care, Nottingham City Clinical Commissioning Groups and Nottinghamshire County Clinical Commissioning Groups (excluding Bassetlaw), Nottinghamshire, UK; ${ }^{4}$ Children's Integrated Commissioning Hub, Nottinghamshire, UK

\subsection{6/archdischild-2018-rcpch.157}

Aim The aim of our working group was to ensure the health outcome measures for Children in Care (CIC) reported by Providers were consistent, relevant and achievable. An objective of the framework was to be an accountable system, where the partners hold themselves to account through the framework, linked by a shared ambition.

Methods

- A service improvement forum was already in place following a long process of service mapping across social care, CIC health teams and CAMHS

- A workshop was held to establish what each service deemed important health outcomes. This was analysed and themes and specifics produced

- Members of the team met with the CIC Council to obtain their views about health outcomes and reporting

- Commissioners, Providers and Designated CIC professionals met to refine a document 'CIC health outcomes framework'

Results Themes from CIC Council meeting
- CIC like how personalised the health assessments are, and felt strongly that the information collected and used to inform planning of health services should be personalised and at an individual level

- CIC feel that health services seem more interested in physical health than mental health, but were clear that emotional health and wellbeing is an important issue; this can be difficult to uncover, so indepth assessment, time and creative approaches are needed

- Access to health information when CIC reach adulthood is important

CIC health outcomes framework comprises of

- A 17 page document with 15 performance indicators measured against standards, evidence, assurance, responsible agency

\section{Conclusions}

- National measures/indicators are focused on the timeliness of assessments. Local ambitions and outcomes aim to measure the extent to which we are benefiting the health of the children in our care

- There are multiple interdependencies in the CIC health system, with agencies reliant on others fulfilling their responsibilities. Local partnership of agencies could hold itself to account for its effectiveness in working together if the right outcomes were identified, and subscribed to by all parties

- There are challenges associated with having multiple organisations, including several NHS providers, in the CIC health system, particularly with regard to data collection and information sharing. Logistical and transactional challenges can be mitigated by strong and trusting relationships between partners, and a commitment to solution focused approaches

\section{G162 EVIDENCE THAT AN IMMERSIVE VIRTUAL REALITY SCENARIO CAN BE USED TO TRAIN SAFEGUARDING TO DOCTORS IN PRIMARY CARE}

${ }^{1}$ CR Fertleman, ${ }^{2} X$ Pan, ${ }^{3} S$ Delacroix. ${ }^{1}$ Paediatrics, Whittington Health, London, UK; ${ }^{2}$ Laws, University College London, London, UK; ${ }^{3}$ Computer Science, Goldsmiths University, London, UK

\subsection{6/archdischild-2018-rcpch.158}

Introduction Most child protection will be seen in primary care but is often subtle.

Methods We invited GPs to undertake a medical consultation in a virtual reality 'cave'. We obtained ethical approval from UCL for this being a covert child safeguarding scenario: participants were informed that they were testing the use of Virtual Reality in GP consultation. We produced a simulated consultation using two avatars: Chris, who came for a medically challenging consultation, and his accompanying 6 year old son Tom. Safeguarding cues presented were either subtle or obvious. Chris was angry towards his son, refused to allow Tom to go to the toilet and appeared to swipe at him.

Results We recruited 63 GPs (26 male; 33 female) who ranged in age from 25 to 59 years and had worked between 1 and 36 years. Fourteen GPs failed to detect the safeguarding cues ( 3 in the obvious cue scenario and 13 in the subtle cue scenario). Analysis of the post scenario questionnaire provides useful information about the use of virtual reality in medical 